\title{
An Unusual Anterior Neck Injury [Cut Throat]: A Case Report
}

\author{
NIMKUR L. $\mathrm{T}^{1^{*}}$ MAAN. $\mathrm{N}^{2} \quad$ MGBACHI. $\mathrm{C}^{2}$ \\ 1. Department of ORL, Head and Neck Surgery Jos University Teaching Hospital Jos/Bingham University \\ Teaching Hospital Jos. \\ 2. Department of ORL, Head and Neck Surgery Jos University Teaching Hospital Jos.
}

\begin{abstract}
Introduction -The Neck is prone to injuries that are life threatening due to the presence of vital structures that lie within the neck. Cut throat injuries are located on the anterior neck classically, with dangers to the aero digestive tract and the vascular structures. Case Presentation-A 40 year old farmer presented with injuries on the lateral sides of the neck with an island of normal tissue anteriorly two days after the incidence from a rural hospital, fig 1. Examination revealed an anaemic, dehydrated young man that was not in any respiratory distress. There was complete avulsion of the epiglottis at the base; and the eyes were also plucked. Patient had blood transfusion, tracheostomy, fig 2 and subsequent repair with favourable outcome. Conclusion-Cut throat injuries are relatively uncommon in our environment, but on the increase due to violence in the society (insurgency, ritual killings, armed robbery etc).Prompt identification and referral to the specialist for proper management will reduce morbidity and mortality.
\end{abstract}

Keywords: unusual, anterior neck, injury

DOI: $10.7176 / \mathrm{JHMN} / 63-06$

Publication date: June $30^{\text {th }} 2019$

\section{INTRODUCTION}

The Neck, like other regions of the human body is prone to injuries. These injuries are life threatening as vital structures, including great vessels and aero-digestive tract, lie within the Neck.Cut throat injuries are classically located on the anterior neck anterio-posteriorly, but in this index case, the injury affected the neck from the lateral side as a puncture wound with an island of normal tissue anteriorly (fig 1). This injury passed anterior to the sternomastoid on one side to the other and posteriorly to the Larynx severing the Epiglottis at its base.

Cut throat injuries (CTIs) represent a subset of Neck injuries and their occurrence is not uncommon in our environment. CTI(s) is described as incised injuries or injuries resembling incised injuries to the anterior neck inflicted by a sharp object ${ }^{[11,8,7]}$. They result mostly from suicidal, homicidal attempts or accidental events. However, the motive follows political conflict, land related dispute, family disharmony, robbery ${ }^{\left[{ }^{8}{ }^{6]}\right.}$ and failed attempts of serial killer/Ritualist as in this case.

These injuries can be classified based on the anatomical zones of the neck, as described by Roon and Christesen. Zone I, representing injuries from the clavicle to the Cricoid. Zone II injuries extend between the Cricoid and angle of the Mandible. While Zone III injuries are between the angle of the mandible and base of skull ${ }^{[8]}$. Other forms of classification can be based on Tissue type- aero digestive tract, vascular ${ }^{[8]}$ or muscular; and based on nature of wound as clean, clean-contaminated or contaminated [NRC classification].

Majority present with upper airway emergency with risk of aspiration and dyspnoea necessitating emergency surgical airway (Tracheostomy) ${ }^{[4,1,9]}$. A few CTIs pose no upper airway challenge, yet requiring tracheostomy at wound exploration and repair. Viz a viz tracheostomy is key in management of CTIs ${ }^{[11,4-5,7]}$.

\section{CASE PRESENTATION.}

A 40 years old male farmer presented through the accident and emergency department following a referral from a peripheral Hospital two day following trauma with wounds on both sides of the upper neck (below angle of mandible). The eyes were also plucked out and there was a history of transient loss of consciousness. The speech was muffled, choking sensation at swallowing and dysphagia but no difficulty in breathing.

Examination showed a young man lying calmly and not in respiratory distress, pale, afebrile and dehydrated, egress of saliva and fluid (meals) through the wound. He had obvious left and right sided lacerations with intervening healthy skin and subcutaneous tissue, fig 1 . Both wounds had ragged edges and approximately $2 \mathrm{~cm}$ below the lower border of the mandible. Right side wound measures about $12 \mathrm{~cm} \mathrm{x} 5 \mathrm{~cm}$ from the angle of the mouth. The wound on the left side extends from the angle of mandible to about $5 \mathrm{~cm}$ from the anterior part of the body of mandible, measuring $8 \mathrm{~cm} \times 3 \mathrm{~cm}$. The wounds were covered with slough, necrotic tissue and exuding saliva. The hypo pharynx as visualised through the wounds has an avulsed epiglottis. Pulse rate was-122 per minute and blood pressure was- $130 / 80 \mathrm{mmHgRespiratory}$ rate was 20 per minute with good air entry. Urgent pack cell volume was $20 \%$.He was resuscitated, had three pints of whole blood transfused and a Nasogastric tube passed for feeding. Wound was cleaned and dressed to make it fit for secondary repair. Tracheostomy, fig 2 was done to protect the lower airway and to enhance subsequent secondary repair. The wound was explored via a somewhat 
"modified Gluck-Sorenson" incision, fig 3 made by linking the lower ends of both injuries. The findings were that of a completely avulsed superior $2 / 3$ of the epiglottis that is held in place by the hyoepiglottic ligament and the epiglottis stump. The epiglottis was repaired, suturing the avulsed portion to the stump taking care of the cartilage. Pharyngoplasty was done following mobilisation of mucosa over an indwelling Nasogastric tube. The muscle, subcutaneous tissue and skin were closed in layers. Wound dressing applied. He was continued on parenteral antibiotic, analgesia and $\mathrm{H}_{2}$ antagonist. He did well, decanulated and discharged without any leakage or chocking sensation, fig 4.

\section{DISCUSSION}

Cut throat injuries can involve the hypopharyx, larynx or trachea; and the extent of injury usually determines the mode of presentation. The unusual nature of injury in this index case was responsible for allowing the patient to stay alive for two days before presenting in our accident and emergency department (i.e. sparing the vessels and the airway substantially). While tracheostomy is paramount in the management of CTIs, multidisciplinary approach $^{[10]}$ enhances better prognosis.

In this index case, the eyes were plucked out and the tongue was almost removed, thus the Otorhinolaryngologist, Ophthalmologist, Anaesthesiologist Haematologist and Nutritionist were involved in managing the patient which helped improved the general outcome.

CTIs can present a variety of complications even with the multidisciplinary approach, like - fistula formation, respiratory compromise, etc and even psychiatric tendencies, even though this case is not suicidal; thus management strategy is necessary. CTIs are known to result in prolonged hospital stay, high cost of health care, reduced quality of life and even death ${ }^{[3]}$. This index case had a negative dye test on the seventh post surgery day, but experienced some aspiration while ingesting fluids. This is likely from the repair of the epiglottis and impaired function; this necessitated a longer hospital stay with adequate improvement before discharge. It is also noted that CTIs are on the increase in our environment with the increase incidence of violence as a result of attacks from ritualists, armed robbers, insurgency, etc ${ }^{[2]}$.

\section{CONCLUSION}

Cut throat injuries are relatively uncommon but on the increase in our environment due to increased violence and thus poses continous challenge to the physician in the rural hospital in terms of management. However a prompt identification and appropriate referral will allow for early presentation to the specialist; and hence reduced morbidity and mortality.

*Ethical clearance for the study was obtained from the Ethical Committee of the Hospital and verbal consent from the patient.

\section{REFERENCES}

1) AA Adoga, ND Ma'an, HY Embu, TJ Obindo. Management of Suicidal cut Throat injuries in Developing Nation: Three case report, cases J 2010;3:65

2) A Bakari, MA Usman. Management of Severe Cut Throat injury in Zaria Nigeria. Archives of International Surgery. 2016; 133=135.

3) Aruna Kumar Chappidi, Anita Chilukuri.A Study of incidence, Causes, and Management of cut throat injuries. International Journal of ORLand Head and Neck Surgery 2018, 4 (3)

4) Ezeanolue BC. Management of upper airway in severe Cut Throat injuries. Ari. J Med Sci. 2001;30: 233-235.

5) Ladapo AA: poen injuries of the anterior Neck. Ghana Med. J 1979; 18:182-186

6) Manilal Aich, ABM Khorshed Alam, Debesh Chandra Talukdar, MA Rouf Sarda, Abu Yousuf Fakir, Monir Hossain. Cut Throat injury: Review of 67csaes. Bangladash J Otorhinolaryngl.2011;11:5-13

7) Md Naveed Ahmed, M Sreedhar Rao, S.Muneeruddin Ahmed, M Mahendra Kumar. Cut Throat injuries and its Management: A clinical study of 48 patients. Journal of Evolution of Medical and Dental Sciences 2015; 4(11) 6572- 658

8) Neha Rautela, Veerendra Verma, Shahabah Ali Usman, Anpan Mishra, HP Singh, Sunil Kumar. Cut Throat injuries:the socio-Demographic pattern, causes and outcome at Tertiary care Hospital North India. International Journal of contemporary Research2007; 4(1): 136-140.

9) Onotai LO, Ibekwe U. The pattern of Cut Throat injuries in the University of PortHarcourt Teaching Hospital, PortHarcourt. Niger. J Med. 2010;19: 264-266.

10) Smitha KS, Nethra SS, Rao R, management of Homicidal Cut Throat Open Airway injury. A Case Report. Int J Sci Stud 2016;3(12);310-312

11) Zafarullah Beigh, Rauf Ahmad. Management of cut throat injuries.EJO 2014;30(3):268- 271 


\section{PICTURES}

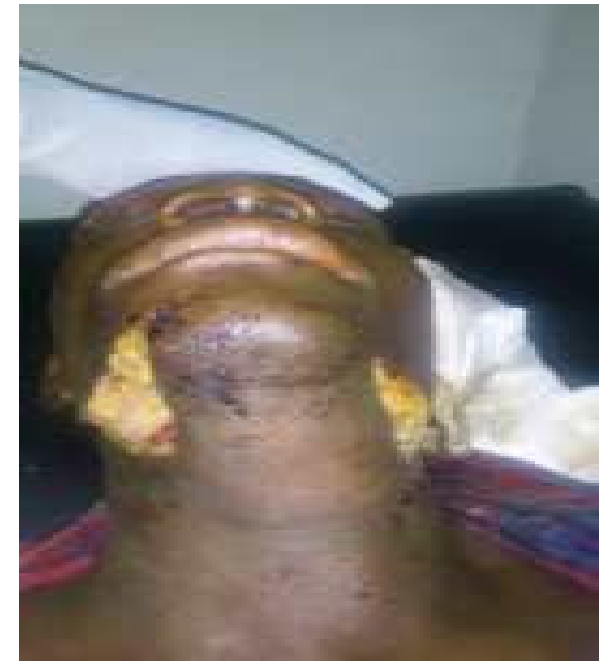

Fig1

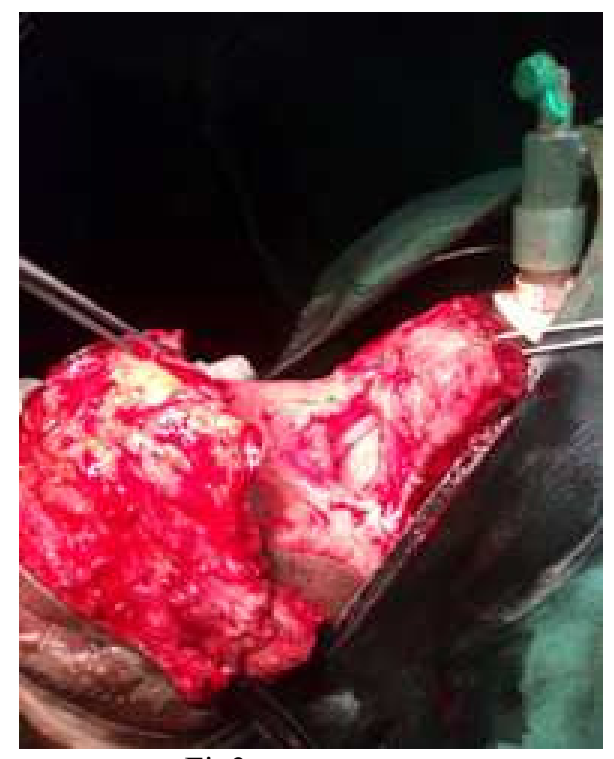

Fig3

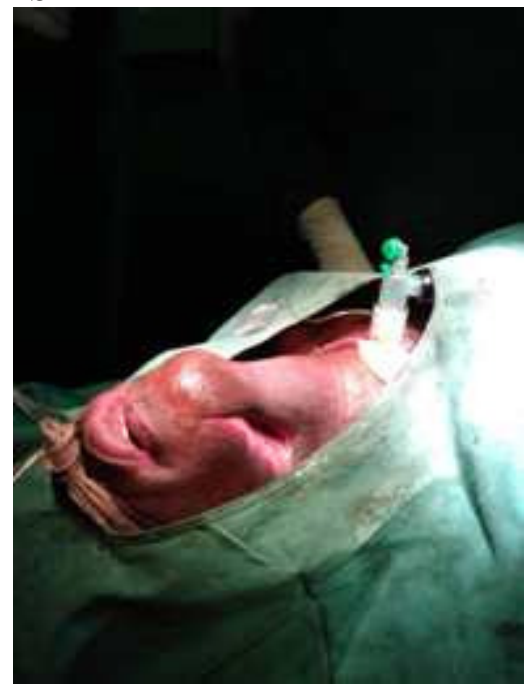

Fig2

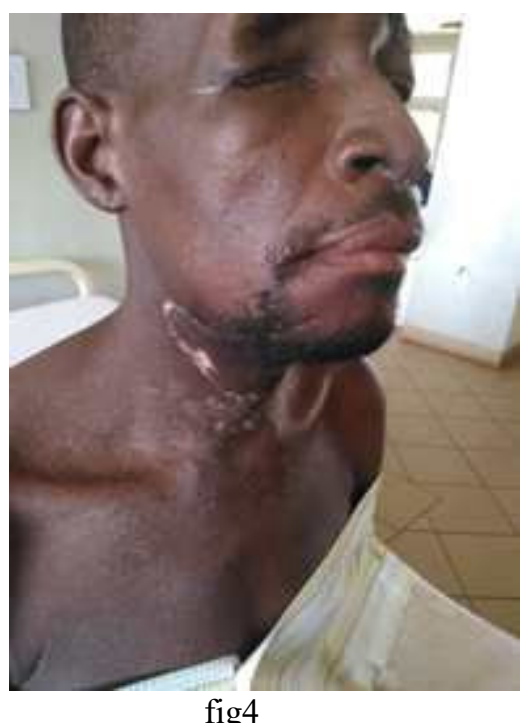

fig4 